\title{
Attendance of fourth Antenatal Care Visit in Ethiopia: Analysis from 2016 Ethiopian Demographic Health Survey
}

Mulugeta Abrha Woldu ( $\square$ mulugetawoldu425@gmail.com )

Tigray Health Research Institute https://orcid.org/0000-0001-7990-8940

Brhane Gebrekidan Ayele

Tigray Health Research Institute

Haftom Weldearegay Gebrehiwot

Mekelle University College of Health Sciences

Araya Medhanyie Abrha

Mekelle University College of Health Sciences

\section{Research}

Keywords: Fourth Antenatal visit, Attendance, Wealth index, EDHS, Ethiopia

Posted Date: December 31st, 2019

DOI: https://doi.org/10.21203/rs.2.19760/v1

License: (c) (i) This work is licensed under a Creative Commons Attribution 4.0 International License. Read Full License 


\section{Abstract}

Background: Globally, approximately 830 women have been reported to die every day due to complications of pregnancy and childbirth. Almost all of these deaths occurred during the third trimester of pregnancy. This could have been reduced by having adequate Antenatal care visits. However, little is known about the determinants of fourth Antenatal care visit. This study is therefore conducted to identify determinants of attendance of fourth Antenatal visits in Ethiopia.

Method: This study was an analysis of data collected by the 2016 Ethiopian Demographic and Health Survey which used a stratified, two-stage cluster sampling design. Bivariate and multivariable regression analysis was done to declare association between independent predictors and attendance of fourth Antenatal care visit.

Result: The independent factors affecting fourth Antenatal visit were highest wealth index (Adjusted Odds Ratio(AOR) $=1.85 ; 95 \%$ Confidence interval $(\mathrm{Cl})(1.41,2.44)$, watching television less than once in a week $(A O R=0.64 ; 95 \% \mathrm{Cl}(0.46,0.88)$, not informed about pregnancy complications during previous visit (AOR= $0.59 ; 95 \% \mathrm{Cl}(0.51,0.70)$ and women who were not given or who did not buy iron tablets/syrup (AOR= $0.64 ; 95 \% \mathrm{Cl}(0.55,0.75)$.

Conclusion: In this study wealth index, frequencies of watching television, information about pregnancy complication, given or bought iron tablets/syrup were the predictors. Therefore integrated service of proper counseling on birth preparedness and complication readiness, Iron folic acid provision by health care providers and other integrated multi-sectoral collaborations are also highly important to improve the wealth index and health literacy of mothers.

\section{Plain English Summary}

The World Health Organization (WHO) recommends that a healthy pregnant woman should have at least four antenatal visits. Yet globally, less than two-thirds of women receive antenatal care at least four times throughout their pregnancy. In developing countries, only a low percentage of women made four or more ANC visits during their pregnancy. Therefore the objective of this study was to assess determinants of fourth ANC visit among women with experience of motherhood in Ethiopia.

This was a secondary analysis of data collected by 2016 Ethiopian Demographic and Health Survey (EDHS); we included only those mothers who started ANC at least once up to 4th visit. Due to all this our sample size was 3,228 mothers. The aim of this study was to identify factors affecting fourth ANC utilization and has revealed that wealth index, frequency of watching television, told about pregnancy complications during pregnancy, given or bought iron tablets/syrup were the predictors. Integrated multisectoral collaborations are also highly important to improve the wealth index and health literacy of mothers.

\section{Background}


Antenatal Care (ANC) is one of the most effective comprehensive interventions that a pregnant woman should receive. This intervention is offered by health care institution with the intention of preventing pregnancy related complications to the mother and unborn baby. ANC consists of risk detection, prevention and management of pregnancy-related diseases, health education and promotion [1-3].

Globally in 2015 the maternal mortality ratio (MMR) was estimated to be $216 / 100,000$ live births. Almost $50 \%$ of these deaths occurred during the third trimester of pregnancy with majority of the deaths happened in low-resource settings that could have been prevented. And also approximately 830 women have been reported to die every day due to complications of pregnancy and childbirth [4].

The World Health Organization (WHO) recommends that a healthy pregnant woman should have at least four antenatal visits. However, the new ANC model recommends eight ANC visits, thereby increasing the opportunities that healthcare providers may detect and address pregnancy related complications. Yet globally, less than two-thirds of women receive antenatal care at least four times throughout their pregnancy. In developing countries only low percentage of women made four or more ANC visits during their pregnancy $[1,3,5-7]$.

In Africa two-thirds of pregnant women have at least one ANC visit and coverage of at least four ANC visits ranging from 44 to 54 percent [8-12]. However, trends indicated that slow progress of fourth ANC visit in Sub-Saharan Africa than in other regions, with only four percent increase in its coverage during the past decade [8].

In Ethiopia the proportion of women who had at least one ANC visit increased from $27 \%$ in 2000 to $62 \%$ in 2016. Despite this notable improvement, only $32 \%$ of women are receiving at least fourth ANC visits [1315]. Several interventions have been recommended by Federal ministry of health to improve ANC visits like health extension program supported by health development army, trained different health professionals, free of charge ANC service and expanding health infrastructures [10]. Regardless of the above efforts, fourth ANC visit is still low.

To the best of our knowledge, little is known about the determinants of fourth ANC visit. Therefore the objective of this study was to assess determinants of fourth ANC visit among women with experience of motherhood in Ethiopia. Thus, our findings can help to design strategies and develop program towards the improvement of service utilization in the country especially with regard to the new recommendation of WHO to have eight ANC visits; which is expected to help decrease the unacceptable maternal, neonatal mortalities and morbidities.

\section{Methods And Materials}

\section{Data source}

This study was an analysis of data collected by the 2016 Ethiopian Demographic and Health Survey (EDHS) [15]. It is the fourth Demographic and Health Survey (DHS) conducted in Ethiopia by the Central 
Statistical Agency (CSA) through the request of the Federal Ministry of Health (FMoH), with the support of United States Agency for International Development (USAID) with the technical assistance of ICF International as part of the International Demographic and Health Survey program known as MEASURE evaluation. The 2016 EDHS sampling used a stratified, two-stage cluster sampling design. A nationally representative sample of 18,008 households and 15,683 women were included in data collection.

\section{Measurement of variables}

The outcome of interest of this study was fourth ANC attendance. To develop the outcome variable "number of ANC visit during pregnancy" for those who had at least one birth five years before the survey were used as starting point. Accordingly, mothers with no ANC follow up were 2481(34.49\%),women's with 1-4 visit were 3228 (44.88\%), those with above five visits were $1465(20.37 \%)$ and $19(0.26 \%)$ responds they Don't know their ANC visit. Following this, because of our aim is to identify factors affecting attendance of fourth ANC; we included only those mothers who started ANC at least once up to 4th visit. Due to all this our sample size was 3,228 mothers. Finally the frequency of reported visits was categorized into two: women who had 4 ANC visits were coded as 1 , and women who had at least one visit but less than 4 visits were coded as 0 . The explanatory variables for the uptake of fourth ANC care were: age of mother, place of residence, marital status, educational level, wealth index, occupation, frequency of reading newspapers or magazines, frequency of listening to the radio, frequency of watching television, sex of household head, family size, parity, given information about pregnancy complications, given or bought iron tablets/syrup and type of pregnancy (wanted or unwanted).

\section{Data analysis}

Data analyses were carried out using SPSS version 21. The dataset includes cases which fulfilled the criteria: age being 15 years and above, and having experienced at least one child birth. Frequency or percentages (tables) were used to represent results of categorical variables. Cross tabulation was used to describe frequency or percentage of study participants. Bi-variable regression analysis (with odds ratio and 95 percent confidence interval) was done to see the association of individual variables with the fourth ANC visit. Variables with $p<0.25$ at bi-variable analysis were entered to multivariable logistic regression analysis using the forward LR method. Finally, $\mathrm{P}<0.05$ in multivariable analysis were considered to declare association between independent predictors and fourth ANC visit.

\section{Results}

\section{Background characteristics of study participants}

A total of 3,228 women aged 15 to 49 years of age who had at least one birth five years before the survey were interviewed. Above three fourth $2534(78.5 \%)$ of the mothers were rural residents and half of the mothers $1662(51.5 \%)$ had family members greater than 5 . Half $1657(51.3)$ of the participants were in age range of 20-29 years. Regarding the educational status $1780(55.1 \%)$ of the participants didn't attend formal education. Above three fourth 2558(79.2) of households were headed by male. Majority 
$2968(92 \%)$ of the mothers were married and $2468(76.5 \%)$ had low parity ( $<2$ child). Regarding the wealth status above a quarter $864(26.8 \%)$ were in category of poorest and below one fourth $753(23.3 \%)$ were richest household [Table 1].

\section{Communication characteristics of study participants}

Majority of the participants 2975(92.2\%) were not reading newspapers or magazines at all. Around three fourths $2359(73 \%)$ did not listen radio at all and above three fourth of them $2455(76.1 \%)$ did not watch television [Table 2].

\section{Pregnancy related characteristics of the study participants}

Above half $1902(58.9 \%)$ of mothers were not told about pregnancy complication during ANC. Sixty one percent $(n=1994)$ of the participants were given or bought iron tablet/syrup. Concerning the type of pregnancy, 2576(79.8\%) of the pregnancy were not wanted initially [Table 3].

\section{Factors associated with attendance of fourth ANC}

In multivariable logistic regression analysis, four variables (wealth index, frequency of watching television, information about pregnancy complications and given or bought iron tablets/syrup during pregnancy) were the significant factors. Accordingly, t pregnant mothers from riches households were 1.85 times $(A O R=1.85 ; 95 \% \mathrm{Cl}(1.41,2.44))$ more likely to visit fourth ANC than the mothers from poorest household. Pregnant mothers who watch television less than once in a week were $36 \%(A O R=0.64 ; 95 \% \mathrm{Cl}$ $(0.46,0.88)$ less likely to attend fourth ANC than those who watch television at least once per week. There were lower odds $(A O R=0.59 ; 95 \% \mathrm{Cl}(0.51,0.70)$ of ANC visit among women who were not informed about pregnancy complications compared to those who were informed during the first ANC. Also, women who were not given or who did not buy iron tablets/syrup during pregnancy were $36 \%$ times less likely to visit fourth ANC when compared to those women who were given or bought iron tablets/syrup (AOR=0.64; $95 \% \mathrm{Cl}(0.55,0.75)[$ Table 4].

\section{Discussion}

The aim of this study was to identify factors affecting fourth ANC utilization and has revealed that wealth index, frequency of watching television, told about pregnancy complications during pregnancy, given or bought iron tablets/syrup were the predictors. Women with higher wealth index were more likely to attend fourth ANC than poorest mothers. However, there was no linear increase in adjusted odds ratio as the wealth status increased from poorer to richer. Study in line with this result from Nepal indicated that women living in the richest circumstance visit ANC much more frequently than those in the poorest [16] also studies from Ethiopia [17, 18], Kenya [19] support this result. This might be due to access to financial resources that could have enabled women to attend antenatal services frequently. Thus, promoting income generating activities can improve complete ANC visit. Pregnant mothers watching television less than once a week was less likely to attend fourth ANC visit than those who watch 
television at least once per week. This result is consistent with a systematic review done in low and middle income countries [20], Nepal [21] and Ethiopia [18], these studies showed that exposure to media leads to frequent ANC attendance. Mothers might get information on timing and number of Ante natal visits, generally what and where to receive the services. So promoting information and communication in the community using Information Education Communication materials is important for Antenatal care service utilization [22,23]. There was lower attendance of antenatal care among women who were not told about pregnancy complication than those told about pregnancy complication during their previous Antenatal care. This is supported by a study done in Tigray, Ethiopia which indicates that advice during ANC leads to frequent attendance of ANC [24]. Also a study from Sub-Saharan Africa showed there was a high unmet need for information on pregnancy complications [25]. Generally this could be due to; if mothers counseled during the earlier visits about their pregnancy status properly, they can continue their visits till the recommended one. The study also indicates that, women who are not given or who did not buy iron tablets/syrup during their pregnancy were $36 \%$ times less likely to visit ANC when compared to their counterparts. This could be due to receiving adequate counseling on the importance of recommended ANC visit while they are taking or buying IFA by providers improve attendance.

The strength of this survey; it was a population-based study with a large sample size which was nationally representative, conducted thoroughly using standard protocols and trained research assistances with response rate of $98.0 \%$. Nonetheless, the survey had some limitations. The data were self-reported and it was a retrospective study making the information collected subjected to recall bias. And also the data during analysis was un-weighted so this might introduced sampling error. However, an effort was made to reduce the recall bias by analyzing data on the most recent pregnancy within five years of the survey.

\section{Conclusion}

In this study wealth index, frequency of watching television, informed about pregnancy complications during pregnancy, given or bought iron tablets/syrup were the predictors. Focusing on to the poorest population like providing transport service to the community specifically for remote areas, general awareness in communities should be raised on the importance of the number and timing of ANC visits. Integrated service like proper counseling on birth preparedness and complication readiness and IFA provision by health care providers are critically important. Additionally other integrated multi-sectoral collaborations are also highly important to improve the wealth index and health literacy of mothers. Orientation to journalists and increasing media coverage about ANC utilization is required. Furthermore, increasing the capacity of health professionals is also crucial.

\section{Declarations}

\section{Ethics approval and consent to participate}


Tigray health research institute ethical committee ruled that no formal ethical approval is required for this particular study and online permission was obtained from measure DHS project website to access the dataset.

\section{Consent for publication}

'Not applicable for this'

\section{Availability of data and materials}

"The datasets generated and/or analyzed during the current study are available from MEASURE DHS project but restrictions apply to the availability of these data, which were used under license for the current study, and so are not publicly available. Data are however available from the MEASURE DHS project upon reasonable online request".

\section{Competing interests}

The author(s) declare that they have no competing interests.

\section{Funding}

'Not applicable'

\section{Authors' contribution}

MAW: Carried out the conception and designing the study, performed statistical analysis and wrote the manuscript.

BGA: Conducted the conception and designing the study.

HWG and AMA: critically evaluated and made progressive suggestions throughout the manuscript. All of the authors read and approved the final draft of the manuscript.

\section{Authors' information}

MAW: MPH in Nutrition, Tigray Public Health Research Institute, Tigray, Ethiopia.

BGA: MPH in General public Health, Tigray Public Health Research Institute, Tigray, Ethiopia.

HWG: MSc in Maternal and Reproductive Health, Mekelle University, College of Health Sciences, Department of Midwifery

AMA: PhD in General Public Health, Mekelle University, College of Health Sciences, School of Public Health

\section{Acknowledgements}


Not applicable

\section{Abbreviations}

ANC Antenatal Care

CSA Central Statistics Agency

EDHS Ethiopia Demographic Health Survey

IFA Iron Folic Acid

PHC Population and Housing Census

USAID United state of America International Development

\section{References}

1. Otolorin E, Gomez P, Currie S, Thapa K, Dao B. Essential basic and emergency obstetric and newborn care: from education and training to service delivery and quality of care. Int J Gynaecol Obstet. 2015;130(2):007.

2. Chorongo D, Okinda FM, Kariuki EJ, Mulewa E, Ibinda F, Muhula S, et al. Factors influencing the utilization of focused antenatal care services in Malindi and Magarini sub-counties of Kilifi county, Kenya. Pan Afr Med J. 2016;25(Suppl 2).

3. Tuncalp, Pena-Rosas JP, Lawrie T, Bucagu M, Oladapo OT, Portela A, et al. WHO recommendations on antenatal care for a positive pregnancy experience-going beyond survival. Bjog. 2017;124(6):860-2.

4. World health statistics 2016: monitoring health for the SDGs, sustainable development goals.

5. Central Statistical Agency [Ethiopia].2014. Ethiopia Mini Demographic and Health Survey 2014. Addis Ababa, Ethiopia.

6. Wang W, Alva S, Wang S, Fort A. Levels and Trends in the Use of Maternal health Services in Developing Countries: DHS Comparative Reports Number 26, 2011.

7. WHO, UNICEF. Antenatal Care in Developing Countries: An analysis of trends, levels and differentials, 1990-2001: Promises, achievements and missed opportunities.

8. Lincetto O, Mothebesoane-Anoh S,Gomez P, Munjanja S. Antenatal Care. Opportunities for Africa's Newborns.

9. Dahiru T, Oche OM. Determinants of antenatal care, institutional delivery and postnatal care services utilization in Nigeria. The Pan African Medical Journal. 2015;21:321.

10. The Federal Democratic Republic of Ethiopia Ministry of Health(FDREMOH). Health Sector Transformation Plan (HSTP): 2015/16 - 2019/20 (2008-2012 EFY) 2015. 
11. C.O. Asweto, J.R. Aluoch, C.O. Obonyo, J.O. Ouma. Maternal Autonomy, Distance to Health Care Facility and ANC Attendance: Findings from Madiany Division of Siaya County, Kenya American Journal of Public Health Research2014;2(4):153-8.

12. The Government of Tigray National Regional State Bureau of Health (TRHB). Tigray Regional Health Bureau 2007 EFY Annual Profile Mekelle,2015.

13. Central Statistical Agency [Ethiopia] and ICF International. 2012. Ethiopia Demographic and Health Survey 2011. Addis Ababa, Ethiopia and Calverton, Maryland, USA: Central Statistical Agency and ICF International.

14. Central Statistical Authority [Ethiopia] and ORC Macro. 2001. Ethiopia Demographic and Health Survey 2000. Addis Ababa, Ethiopia and Calverton, Maryland, USA: Central Statistical Authority and ORC Macro.

15. Central Statistical Agency (CSA) [Ethiopia] and ICF. 2016. Ethiopia Demographic and Health Survey 2016.Addis Ababa, Ethiopia, and Rockville, Maryland, USA: CSA and ICF. .

16. Sah R, Gaurav K, Baral D, Jha N, Pokharel P. Antenatal Care Practices In Hilly Area Of Eastern Region Of Nepal. Journal Of Chitwan Medical College. 2013;3(4):12-5.

17. Tarekegn SM, Lieberman LS, Giedraitis V. Determinants of maternal health service utilization in Ethiopia: analysis of the 2011 Ethiopian Demographic and Health Survey. BMC Pregnancy and Childbirth. 2014;14:161-.

18. Birmeta K, Dibaba Y, Woldeyohannes D. Determinants of maternal health care utilization in Holeta town, central Ethiopia. BMC Health Services Research. 2013;13:256-.

19. Gitonga E. Determinants of Focused Antenatal Care Uptake among Women in Tharaka Nithi County, Kenya. Hindawi Advances in Public Health. 2017:4.

20. Banke-Thomas OE, Banke-Thomas AO, Ameh CA. Factors influencing utilisation of maternal health services by adolescent mothers in Low-and middle-income countries: a systematic review. BMC Pregnancy and Childbirth. 2017;17:65.

21. Deo KK, Paudel YR, Khatri RB, Bhaskar RK, Paudel R, Mehata S, et al. Barriers to Utilization of Antenatal Care Services in Eastern Nepal. Frontiers in Public Health. 2015;3:197.

22. Abosse Z, Woldie M, Ololo S. Factors Influencing Antenatal Care Service Utilization in Hadiya Zone. Ethiopian Journal of Health Sciences. 2010;20(2):75-82.

23. Tewodros B, G/Mariam A, Dibaba Y. Factors Affecting Antenatal Care Utilization In Yem Special Woreda, Southwestern Ethiopia. Ethiop J Health Sci March 2009;19(1).

24. Tsegay Y, Gebrehiwot T, Goicolea I, Edin K, Lemma H, Sebastian MS. Determinants of antenatal and delivery care utilization in Tigray region, Ethiopia: a cross-sectional study. International Journal for Equity in Health. 2013;12:30-.

25. Nikie'ma Ba, Beninguisse G, Haggerty JL. Providing information on pregnancy complications during antenatal visits: unmet educational needs in sub-Saharan Africa. Health Policy and Planning. 2009;24:367-76. 


\section{Tables}

Table 1: Socio-eco-demographic characteristics of participants on fourth ANC utilization in Ethiopia, $2016(\mathrm{~N}=3228)$

\begin{tabular}{|c|c|c|c|}
\hline \multicolumn{2}{|c|}{ Background Characteristics } & Number & Percent \\
\hline \multicolumn{4}{|l|}{ Residence } \\
\hline & Urban & 694 & 21.5 \\
\hline & Rural & 2534 & 78.5 \\
\hline \multicolumn{3}{|l|}{ Family size } & \\
\hline & $\begin{array}{l}<5 \text { memoers } \\
>5 \text { members }\end{array}$ & $\begin{array}{l}1500 \\
1662\end{array}$ & $\begin{array}{l}40.5 \\
51.5\end{array}$ \\
\hline \multicolumn{4}{|c|}{ Age of mothers in years } \\
\hline & $15-19$ & 192 & 6.0 \\
\hline & $20-29$ & 1657 & 51.3 \\
\hline & $30-39$ & 1136 & 35.2 \\
\hline & $40-49$ & 243 & 7.5 \\
\hline \multicolumn{4}{|c|}{ Educational status } \\
\hline & No education & 1780 & 55.1 \\
\hline & Primary & 1044 & 32.4 \\
\hline & Secondary & 277 & 8.6 \\
\hline & Higher & 127 & 3.9 \\
\hline \multicolumn{4}{|c|}{ Sex of house hold head } \\
\hline & Male & 2558 & 79.2 \\
\hline Marithl atohn & Female & 670 & 20.8 \\
\hline Mtirlar stas & Never married & 20 & 0.6 \\
\hline & Married & 2968 & 92.0 \\
\hline & Living with partner & 32 & 1.0 \\
\hline & Widowed & 39 & 1.2 \\
\hline & Divorced & 132 & 4.0 \\
\hline Damito & Separated & 37 & 1.2 \\
\hline Fanily & Low multipara & 2468 & 76.5 \\
\hline & Grand multipara & 760 & 23.5 \\
\hline Wearuir stalus & Poorest & 864 & 26.8 \\
\hline & Poorer & 594 & 18.4 \\
\hline & Middle & 535 & 16.6 \\
\hline & Richer & 482 & 14.9 \\
\hline & Richest & 753 & 23.3 \\
\hline
\end{tabular}

Table 2: Communication characteristics of participants on fourth ANC utilization in Ethiopia, $2016(\mathrm{~N}=3228)$ 


\begin{tabular}{llll}
\hline Characteristics & Number & Percent \\
\hline Frequency of reading newspaper or magazine & & \\
$\quad$ Not at all & 2975 & 92.2 \\
$\quad$ Less than once a week & 187 & 5.8 \\
$\quad$ At least once a week & 66 & 2.0 \\
& & \\
Frequency of listening to radio & 2359 & 73.0 \\
$\quad$ Not at all & 458 & 14.2 \\
Less than once a week & 45.8 \\
At least once a week & 411 & 12.8 \\
Frequency of watching television & & \\
$\quad$ Not at all & 2455 & 76.1 \\
Less than once a week & 312 & 9.7 \\
At least once a week & 461 & 14.2 \\
\hline
\end{tabular}

Table 3: pregnancy related characteristics of participants on fourth ANC utilization in Ethiopia, $2016(\mathrm{~N}=3228)$

\begin{tabular}{lll}
\hline Characteristics & Number & Percent \\
\hline Told about pregnancy complications & & \\
No & 1902 & 58.9 \\
Yes & 1326 & 41.1 \\
Nuring pregnancy, given or bought iron tablets/syrup & & \\
No & 1234 & 38.2 \\
Yes & 1994 & 61.8 \\
Type of pregnancy(un/wanted) & & \\
Then & 2576 & 79.8 \\
Later & 465 & 14.4 \\
No more & 187 & 5.8 \\
\hline
\end{tabular}

Table 4: Logistic regression analysis on fourth ANC utilization among pregnant mothers in Ethiopia, 2016(n=3228) 
Characteristics

\begin{tabular}{llll}
\hline Yes, $\mathbf{N}$ & No, $\mathbf{N}(\%)$ & COR & AOR
\end{tabular}

(\%)

Wealth status

\section{Poorest}

Poorer

Middle

Richer

Richest

Place of residence

Urban
Rural

Family size

$$
\begin{aligned}
& <5 \text { members } \\
& >5 \text { members }
\end{aligned}
$$

Age of the participants

15-19 years

20-29 years

30-39 years

40-49 years

Educational status

No education

Primary

Secondary

Higher

Sex of house hold head

$$
\begin{aligned}
& \text { Male } \\
& \text { Female }
\end{aligned}
$$

Marital status

Never married

Married

partner

Living with

Widowed

Divorced

$\begin{array}{lll}209(24.2) & 655(75.8) & 1 \\ 204(34.3) & 390(65.7) & 1.64(1.30- \\ & & 2.06) \\ 180(33.6) & 355(66.4) & 1.59(1.25- \\ & & 2.06) \\ 192(39.8) & 290(60.2) & 2.08(1.63- \\ & & 2.64) \\ 351(46.6) & 402(53.4) & 2.74(2.26- \\ & & 3.38)\end{array}$

316(45.5) 378(54.5) 1

$820(32.4) \quad 1714(67.6)$

$$
\text { 2.07) }
$$

1

1.56(1.23-

1.97)*

$1.50(1.18-$

1.90)*

1.81(1.41-

2.32)*

$1.85(1.41-$

2.44)*

NS

515(32.9) 1051(67.1) 1

621(37.4) 1041(62.6) 1.22(1.05- NS

1.41)

$\begin{array}{lll}65(33.9) & 127(66.1) & 1.01(0.67- \\ & & 1.50) \\ 587(35.4) & 1070(64.6) & 1.08(0.81- \\ & & 1.43) \\ 402(35.4) & 734(64.6) & 1.08(0.80- \\ & & 1.44) \\ 82(33.7) & 161(66.3) & 1\end{array}$

525(29.5) 1255(70.5) 0.41(0.29- NS

403(38.6) 641(61.4) $0.62(0.43-$

$0.89)$

$144(52) \quad 133(48) \quad 1.07(0.70-$ 1.62)

64(50.4) 63(49.6) 1

884(34.6) 1674(65.4) 1

$\begin{array}{lll}252(37.6) \quad 418(62.4) & 1.14(0.96-\end{array}$

NS

10(50) $10(50) \quad 1$

1947(65.6) $1021(34.4) \quad 0.52(0.22-\quad$ NS

$19(59.4) \quad 13(40.6) \quad 1.46(0.47-$

17(43.6) 4.50$)$

$17(43.6) \quad 22(56.4) \quad 0.77(0.26-$

2.28)

$51(38.6) \quad 81(61.4) \quad 0.63(0.26-$

1.62) 
Separated

Parity
18(48.6)

$19(51.4)$

$0.95(0.32-$

2.81)

\begin{tabular}{|c|c|c|}
\hline 895(36.3) & 1573(63.7) & $\begin{array}{l}1.23(1.03- \\
1.46)\end{array}$ \\
\hline 241(31.7) & $519(68.3)$ & 1 \\
\hline 898(34.9) & 1678(65.1) & 1 \\
\hline 169(36.3) & $296(63.7)$ & $\begin{array}{l}1.08(087- \\
1.31)\end{array}$ \\
\hline $69(36.9)$ & 118(63.1) & $\begin{array}{l}1.09(0.80- \\
1.49)\end{array}$ \\
\hline
\end{tabular}

Frequency of reading newspaper/ magazine
Not at all

Less than once a

week

week

Not at all

Less than once a

week

At least once a

1004(33.7)

$100(53.5)$

$32(48.5)$

1971(66.3)

$0.54(0.33-$

$0.88)$

$1.22(0.69-$

2.14)

$87(46.5)$

$34(51.5)$

771(32.3) 1588(67.3)

$0.61(0.49-$

182(39.3) 276(60.3)

$0.75)$

$0.82(0.63-$ 1.08)
Frequency of listening to radio

NS

NS

183(45.5) 228(55.5) 1

week

At least once a

Frequency of watching television
Not at all

Less than once a

week $\begin{array}{lll}797(32.5) \quad 1658(67.5) & 0.46(0.38- \\ & & 0.57)\end{array}$

104(33.3) 208(66.7)

$0.48(0.36-$ $0.65)$

At least once a week 235(51)

226(64.8) 1

Told about pregnancy complications

No

Yes
1356(71.3)

736(55.5)

$590(44.5) \quad 736(55$
iron tablets/syrup

\begin{tabular}{llll} 
No & $353(28.6)$ & $881(71.4)$ & $0.62(0.53-$ \\
& & & $0.72)$ \\
Yes & $783(39.3)$ & $1211(60.7)$ & 1 \\
\hline
\end{tabular}

$0.50(0.43-$ $0.58)$

During pregna

353(28.6)

$881(71.4)$ 1

$0.82(0.66-$ 1.09)

$0.64(0.46-$ $0.88) *$

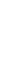

NB: * Refers statistically significance, NS: Non-significant 